\title{
Novas palavras para antigos caminhos ${ }^{1}$
}

Eugenio Barba*

Tradução do italiano: Patrícia Furtado de Mendonça

"Cada época sonha com a época anterior", dizia Jules Michelet. E assim, fantasiando teatros do passado, inventamos nossas técnicas percorrendo antigos caminhos. Sentimos a necessidade de forjar palavras que nos pertencem para evocar nossas miragens e supostos progressos. É bom refletir sobre os nomes dos caminhos antigos, mas também é útil rebatizar regularmente os termos de nossa língua de trabalho.

Hoje os atores usam técnicas que não buscam formas fixas nem respeitam regras do jogo bem definidas, como acontece no balé, no Kabuki ou no Kathakali, espetáculos que têm formas codificadas. Estou falando dos atores daqueles teatros que não possuem ou não querem ter uma tradição codificada, que não se caracterizam por uma estilização específica ou por um comportamento que possa ser reconhecido. São teatros que têm um destino ou uma vocação particulares: vivem como se estivessem sempre em statu nascendi, inclusive quando já têm longa experiência.

Em geral são chamados de teatro experimental, teatro laboratório ou, simplesmente, teatro de grupo. Correspondem a uma importante tradição independente. Uma "tradição do novo" mais parece um oximoro poético, e certamente é uma contradição. Mas essa contradição é uma parte essencial da história do teatro moderno.

\footnotetext{
*Eugenio Barba nasceu em Gallipoli, na Itália, em 1936. Estudou no colégio militar de Nunziatella em Nápoles. Em 1954 foi para a Noruega onde formou-se em Literatura francesa e norueguesa e História das religiões na Universidade de Oslo. Em 1961, foi para a Polônia estudar direção teatral, abandonando porém a Escola Estatal de Teatro, sediada em Varsóvia, para se unir ao teatro de Jerzy Grotowski. Em 1963, foi para a India onde estudou Kathakali. Voltou a Oslo em 1964, onde fundou o Odin Teatret. Em 1979 fundou a ISTA (International School of Theatre Anthropology) e em 2002 o CTLS (Centre for Theatre Laboratory Studies). Dirigiu até então 76 produções com o Odin Teatret e com o Theatrum Mundi Ensemble. Trata-se de um dos grandes mestres do teatro ainda vivo, cuja atuação vai além da concepção de espetáculos, abrangendo o âmbito da pedagogia, da ação social, da formação do ator/indivíduo. O conjunto de sua obra serve de inspiração para inúmeros atores e grupos de teatro que resistem pelo mundo afora.
} 
É óbvio que a tradição do novo não pode aplicar procedimentos que garantam resultados dentro de uma margem de erro razoável. No entanto, esse teatro que está perpetuamente em statu nascendi, ou que é um eterno principiante, foi o paradoxo vivo que inspirou Stanislávski, Craig, Copeau, Brook e Grotowski.

São muito usadas expressões como "língua do corpo", “língua do teatro," “língua do ator". Mas no contexto do teatro que vive como se estivesse sempre em statu nascendi, ensinar técnicas de atuação nunca foi o mesmo que ensinar uma "língua" difícil que, todavia, tem uma estrutura definida. É possível transmitir o conhecimento e a prática do latim, do sânscrito ou do grego antigo com métodos experimentais, e qualquer pessoa pode aprender essas línguas levando mais tempo ou menos tempo.

Mas um teatro em statu nascendi e eterno principiante funciona de outra maneira: nele, o ensinamento só pode ativar e inspirar um processo pessoal. Talvez possa chegar a um bom resultado, mas, infelizmente, nem sempre alcança seu objetivo, apesar do empenho e da dedicação.

Estou me referindo a técnicas de ator que só funcionam como tal depois de serem incorporadas. Ao olhar para trás, quem as incorporou poderá esquecer as muitas derrotas, e mostrar as poucas descobertas. São técnicas claras e consistentes apenas se forem observadas a posteriori. Na verdade, cada uma dessas técnicas é uma micro-história particular, a consequência de uma biografia que nunca irá se repetir.

Todos esses paradoxos e contradições causam veneração e rejeição, ceticismo e fetichismo ao redor da ideia das técnicas do ator. Então nos vemos diante de técnicas particulares, técnicas que o estudioso italiano Franco Ruffini compara aos ornitorrincos.

Os ornitorrincos são mamíferos, mas sua natureza parece contradizer as classificações naturais: são mamíferos que colocam ovos, têm dentes e têm bico, possuem extremidades palmadas como as dos patos e ainda são dotados de um pequeno esporão, perigoso e venenoso, que fica nas patas traseiras.

As técnicas do ator também possuem esporões venenosos. É impossível ensiná-las de forma metódica, passo após passo, como se fossem um pacote de conhecimentos que podem ser reutilizados: por exemplo, da mesma maneira em que podemos transmitir receitas de cozinha, rotas aéreas ou navais, ou mesmo as posturas básicas do jogo de tênis. Também são diferentes das chamadas "técnicas do corpo", aquelas que são aprendidas inconscientemente pelo simples fato de se crescer num determinado ambiente. As técnicas do ator não são técnicas do corpo, mas da personalidade, de um corpo-mente que é particular e único. 
Por que será, então, que durante todo o teatro do século XX materializou-se a ideia de um treinamento do ator? Como foi que nasceu a ideia de uma aprendizagem que não busca uma forma, um estilo ou um gênero de espetáculo pré-estabelecido? Foi superficialidade ou ilusão?

Na realidade, tratou-se sempre de um antitreinamento ou de uma ficção pedagógica. Foi uma revolta, uma necessidade de destruir o teatro para reinventá-lo. Os exercícios não precisavam adestrar o ator para um teatro que tivesse um perfil preciso e reconhecível. Muito pelo contrário, tendiam a libertá-lo dos comportamentos estereotipados, dos condicionamentos cênicos, das atitudes miméticas e dos clichês dos atores.

No teatro, a palavra "clichê" dá medo. Todo ator experiente tem sua própria personalidade cênica, seu próprio comportamento recorrente, seu próprio modo peculiar de administrar as energias, um ritmo reconhecível do seu próprio bios cênico. Como podemos distinguir essa reconhecibilidade recorrente dos famigerados clichês? Mais do que uma pergunta técnica, essa é uma inquietação que diz respeito à disciplina pessoal do ator. Não tem nada a ver com a estética, mas com a angústia de se tornar artisticamente estéril: estagnar.

Antes de mais nada, os exercícios e o treinamento ensinam disciplina. Essa é outra palavra que dá medo. Um reflexo automático nos faz pensar imediatamente em alguém que limita a nossa liberdade impondo regras de pensamento e conduta. Mas na arte, a disciplina oscila entre dois processos diferentes que, na prática, estão misturados: de um lado, a ação de aprender (em latim: discere); do outro, a coerência ao respeitar rigorosas regras que são autoimpostas.

Os exercícios inventados no século XX provêm tanto da ânsia de experimentar e mudar quanto da ânsia de se submeter a uma disciplina. Mas também refletem o desejo de levar o ator a uma zona não domesticada da própria paisagem interior.

Quando os resultados emergem, são diferentes para cada pessoa. São obtidos por meio de um longo percurso feito de prática, pensamento e repensamento, fadiga, tentativas infinitas e erros intermináveis. No final desse percurso, podem surgir alguns resultados cujo valor é evidente. Mas essa evidência não é suficiente para quem deseja se apropriar desses conhecimentos. Não basta saber o quê encontrar, se a pessoa não sabe como.

Stanislávski explicava esse dilema usando uma imagem muito clara. Dizia que se sentia como um explorador de ouro que tinha passado anos escavando montanhas de terra e pedras. Cem vezes caiu abatido no chão, e cento e uma vezes ele se levantou. No final, reúne um punhado de ouro em estado bruto. Ele o mostra. Todos compreendem o valor de seu 
trabalho e de sua pesquisa pela força da evidência. Está tudo ali, dentro de um punho. Mas eles também entendem que saber que o ouro existe e pode ser encontrado não significa, necessariamente, saber como encontrá-lo. E, principalmente, todos se dão conta de que a técnica para encontrar o ouro consiste em $99 \%$ do trabalho do quebrador de pedras e $1 \%$ da obstinação de um apaixonado.

O verdadeiro problema não é aprender, mas aprender a desaprender. Essa exortação à sábia ignorância, a extrair o difícil do difícil, foi a bússola do Odin Teatret durante meio século.

Os métodos, as teorias e as imagens que tentam traduzir o saber incorporado do ator - aquilo que chamamos de "a sua técnica" - servem para ativar visões e línguas pessoais que são provisórias. Podem assumir a credibilidade de uma mitologia que funcionou para algumas pessoas e que pode, em alguns casos, funcionar para outras. Nunca são métodos, teorias ou imagens garantidas.

É possível listar uma série de regras técnicas e artísticas. Mas quando alguém se depara com um processo criativo, cada "regra" funciona tanto pelo direito como pelo avesso. Em alguns casos, negar uma regra e se esforçar para contradizê-la até o final pode ser mais eficaz do que se angustiar para aplicá-la.

Somos frequentemente obrigados a disfarçar com teorias e receitas as palavras que usamos ao falar das técnicas do ator, ainda que elas não sejam nem teorias nem receitas. Na maioria das vezes, esse disfarce é o único modo de dar credibilidade não às próprias palavras, mas ao que elas acenam.

Tendemos a desconfiar das palavras. Mas, na prática, elas nunca são imprecisas quando usadas num determinado contexto e numa relação cara-a-cara com tempo suficiente para metabolizar incompreensões e erros. As palavras são perigosas quando dão a ilusão de definir, uma vez por todas, o próprio conteúdo e a própria direção. Às vezes são palavras que nutrem. E como tudo o que nutre, elas também estão cheias de vírus. De tanto repeti-las, sua capacidade de nutrir se deteriora, se banaliza, e aí os vírus atacam.

É por isso que estamos sempre mudando as palavras, para que não fiquem estagnadas. As palavras são como bolas de neve. Boas para atingir alguém. Mas não podemos conservá-las por muito tempo, como se fossem pedras ou pepitas. Uma bola de neve pode ser uma arma, mas é também uma pedra d'água. Uma contradição de termos, como as flechas de gelo de 


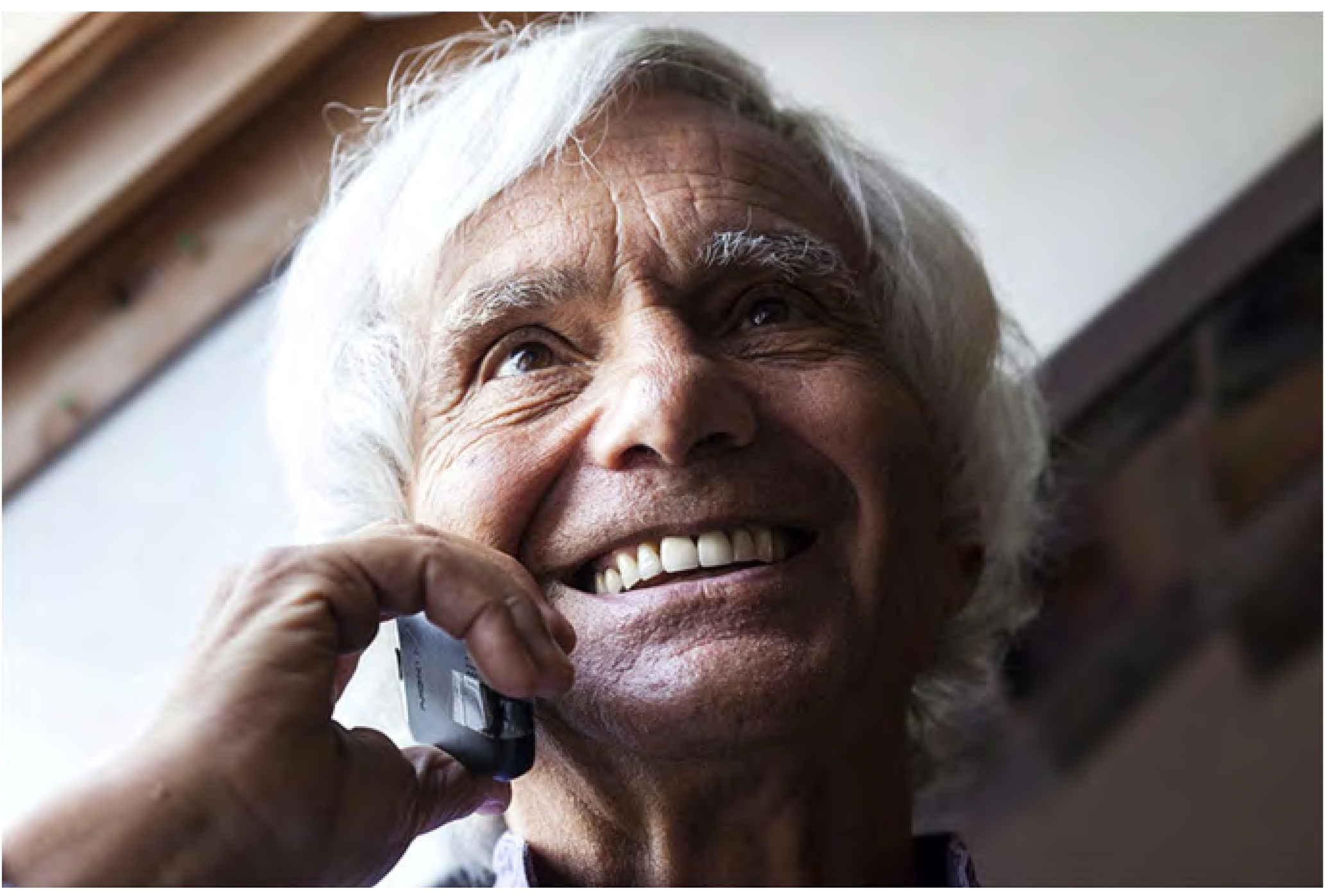

Eugenio Barba

Holstebro - setembro de 2016

Fotografia: Francesco Galli

Fonte: http://odinteatret.dk/ 
Quando estão começando, os atores são dotados de três línguas. E eles só poderão desenvolver as características dessas três línguas se tiverem consciência de cada uma delas. Entrelaçando-as, tornando-as consonantes ou dissonantes, poderão orquestrar uma sinfonia de estímulos sensoriais e mentais dialéticos.

Essas três línguas são: a sonoridade da voz; o sentido das palavras ditas; os gestos e as atitudes que as acompanham. Meyerhold já havia identificado duas línguas - a das reações físicas e a do significado do texto. A essas duas línguas deve-se acrescentar a língua da sonoridade que pode facilmente negar o significado com uma inflexão irônica, patética ou agressiva. Daí a necessidade de uma aprendizagem - o treinamento - cujo objetivo é desenvolver o poder de sugestão da voz, suas possibilidades melodiosas e seus impactos emotivos. As entonações da voz são uma música que provoca associações, atmosferas e estados de ânimo. A língua sonora transmite informações não conceituais que, assim como os harmônicos independentes, comentam o texto continuamente.

Até mesmo a língua da "espontaneidade", das atitudes e dos gestos cotidianos, pode ser submetida a um treinamento para se desvincular de suas conotações óbvias de gesticulação repetitiva. A língua dos clichês, que é típica da nossa personalidade social e privada, pode ser revitalizada por meio de impulsos físicos e mentais que unem tanto realidades distantes entre si quanto pensamentos antitéticos e ideias reciprocamente irreconciliáveis. Um treinamento físico e vocal familiariza o ator com esse modo paradoxal de pensar com todo seu corpo-mente. "Pousar beijos como se fossem um olhar, plantar olhares como se fossem árvores, prender árvores como se fossem pássaros, irrigar pássaros como se fossem heliotrópios". Esse programa, que o chileno Vicente Huidobro propôs para a geração de poetas que eram seus coetâneos, também poderia ser válido para o treinamento do corpo-mente do ator.

Como um oximoro - a imagem contraditória plasmada pelo negro fulgor das palavras de um poeta - o comportamento do ator se torna um claro enigma: evidente por suas consequências sensoriais e emotivas, mas difícil de explicar em termos racionais. Graças a esse processo de poesia mental/somática (não nos esqueçamos que, em grego, poiein significa "forjar materialmente"), o ator transforma clichês físicos e vocais em signos insólitos e eficazes, uma síntese de intenções e estímulos contrastantes que transportam o espectador para um universo de metáforas e autobiografia. 
Hoje, da mistura e do diálogo de suas três línguas, poucos atores sabem destilar outras tantas sombras que sussurram. Se essas sombras se manifestam, o espectador as percebe e sente-se interrogado por seu sussurrar. Três sombras se projetam em direções opostas às das três línguas materiais da sonoridade, do significado e dos dinamismos somáticos. Cada sombra sussurra em sua própria língua: Švejk, tigre e anjo.

A língua de Švejk, o personagem criado por Jaroslav Hašek e adotado por Bertolt Brecht, esconde com as palavras o verdadeiro sentido de suas ações.

A língua do tigre é a do perigo eminente e dissimulado que, às vezes, o espectador intui, mas não sabe como explicar. O tigre não dá um passo sem estar pronto para atacar. Mesmo quando descansa, se prepara para saltar. Quando não se mexe, o perigo é ainda maior. Ferocidade é sua graça. Adora tudo o que é vivo, e o que ele adora, vira sua comida.

A língua do anjo é a mais difícil de explicar. Como a própria etimologia já diz, os anjos são mensageiros em estado puro. Só existem quando realizam uma tarefa impregnada de destino. Sua vida inteira está na mensagem que lhes é confiada. O mensageiro é a mensagem, e a menor nuance da mensagem também é essencial. O anjo se concentra na potência de cada gesto, de cada olhar, de cada sílaba e entonação, da mais suave cadência e da mais fugaz imobilidade. E isso sem ter consciência do que a mensagem diz a quem a recebe. Ele não pretende interpretá-la: apenas a transmite. Conjuga tudo isso com sua cega vocação - incompreensível até para si mesmo - de não ser nada mais que um anjo: um mensageiro consciente de sua incapacidade de saber se há um sentido no que ele transmite, e qual é esse sentido para cada espectador.

Não pensem que estou pegando as palavras pelo rabo e que as faça chiar ao rodopiá-las no ar. Só estou dizendo uma coisa óbvia. Quem de nós nunca fez a experiência, ao menos uma vez, da língua angelical de um ator que nos sussurrou - sem se dar por isso - um dos nossos próprios segredos?

\section{Notas}

1 Discurso de agradecimento em ocasião do título de Doutor Honoris Causa conferido a Eugenio Barba pela Universidade Queen Margaret, de Edimburgo, no dia 01 de julho de 2014. 